\title{
A High-Throughput Microtiter-Based Fungicide Sensitivity Assay for Oomycetes Using $Z^{\prime}$-Factor Statistic
}

\author{
Zachary A. Noel, ${ }^{1,2}$ Alejandro J. Rojas, ${ }^{1,2}$ Janette L. Jacobs, ${ }^{1}$ and Martin I. Chilvers ${ }^{1,2, \dagger}$ \\ ${ }^{1}$ Department of Plant, Soil and Microbial Sciences, Michigan State University, East Lansing, MI 48824 \\ 2 Program in Ecology, Evolutionary Biology and Behavior, Michigan State University, East Lansing, MI 48824 \\ Accepted for publication 22 April 2019.
}

\begin{abstract}
Current methods to quantitatively assess fungicide sensitivity for a diverse range of oomycetes are slow and labor intensive. Microtiterbased assays can be used to increase throughput. However, many factors can affect their quality and reproducibility. Therefore, efficient and reliable methods for detection of assay quality are desirable. The objective of this study was to develop and validate a robust highthroughput fungicide phenotyping assay based on spectrophotometric quantification of mycelial growth in liquid culture and implementation of quality control with $Z^{\prime}$ factor and growth curves. $Z^{\prime}$ factor was used to ensure that each isolate grew enough in the absence of fungicides compared with the negative control, and growth curves were used to ensure active growth at the time of concentration of a fungicide that
\end{abstract}

ABSTRACT

Oomycetes are a group of filamentous osmotrophic eukaryotes primarily known as plant pathogens, but also, they can be pathogens of mammals, ochrophytes, fish, crustaceans, and insects, making them economically and ecologically important (Beakes et al. 2012). Fungicides targeting oomycetes (oomicides) (Govers 2001) are an important tool for managing these pathogens. Testing fungicides in vitro is an essential step in product discovery, efficacy screening, discovery of fungicide resistance mechanisms, and resistance monitoring. The "gold standard" method used to test oomycete or fungal sensitivity to fungicides is by measuring colony growth on fungicide-amended agar medium (Georgopoulos 1982). Herein, we refer to this method as the amended medium assay. In this method, several concentrations of fungicides are amended into agar medium, and colony diameter is monitored, which makes screening hundreds of isolates slow, labor intensive, and expensive. Therefore, designing new methods that increase the throughput of fungicide screening while maintaining data quality is desired (Brent and Hollomon 2007). The Fungicide Resistance Action Committee (FRAC) has established a series of standards for new methods for assessing fungicide sensitivity. The method must

${ }^{\dagger}$ Corresponding author: M. I. Chilvers; chilvers@msu.edu

Current address of A. J. Rojas: Department of Plant Pathology, University of Arkansas, Fayetteville, AR 72701.

Funding: This project was supported by Agriculture and Food Research Initiative competitive grant 2011-68004-30104 from the U.S. Department of Agriculture National Institute of Food and Agriculture, the Michigan Soybean Promotion Committee, the United Soybean Board, the North Central Soybean Research Program, and Valent U.S.A. LLC.

*The $\boldsymbol{e}$-Xtra logo stands for "electronic extra" and indicates that two supplementary figures and four supplementary tables are published online.

The author(s) declare no conflict of interest.

This article is in the public domain and not copyrightable. It may be freely reprinted with customary crediting of the source. The American Phytopathological Society, 2019. reduces growth by $50 \%\left(\mathrm{EC}_{50}\right)$ estimation. $\mathrm{EC}_{50}$ and relative growth values were correlated in a side-by-side comparison with values obtained using the amended medium (gold standard) assay. Concordance correlation indicated that the high-throughput assay is accurate but may not be as precise as the amended medium assay. To demonstrate the utility of the high-throughput assay, the sensitivity of 216 oomycete isolates representing four genera and 81 species to mefenoxam and ethaboxam was tested. The assay developed herein will enable highthroughput fungicide phenotyping at a population or community level.

Keywords: disease control and pest management, techniques be (i) repeatable, (ii) easy to operate, and (iii) inexpensive and amenable to high-throughput format, and (iv) data must be relatable to field sensitivity (http://www.frac.info/monitoringmethods). The method must be validated by comparing the sensitivity of many isolates, both sensitive and resistant, obtained using the new method with the conventional amended medium assay (Förster et al. 2004; Kuhajek et al. 2003; Rampersad 2011).

Spiral dilution plating is a high-throughput assay that was developed to test the sensitivity of various fungal pathogens to fungicides. This method requires a spiral plater and specialized software to estimate the concentration of a fungicide that reduces growth by $50 \%\left(\mathrm{EC}_{50}\right)$ values (Förster et al. 2004). Testing the sensitivity of single-celled organisms to antimicrobial compounds in microtiter plates is common, and efforts to adopt principles of these methods have been applied to filamentous fungi and oomycetes (Cox et al. 2009; Frac et al. 2016; Kuhajek et al. 2003; Olson et al. 2013; Rampersad 2011; Vega et al. 2012). However, these methods are not always applicable to a diverse set of oomycete species. For example, Kuhajek et al. (2003) developed a method for Phytophthora spp. utilizing zoospores to inoculate fungicide-amended broth in microtiter plates and then, measure the optical density (OD) of mycelial growth. Zoospores are desirable, because the inoculum density can be quantified, and a standard amount can be added to each well or a microtiter plate. Zoospore production is not difficult for some oomycetes. However, many Pythium spp. form germ tubes directly from oospores or sporangia rather than producing zoospores (Martin and Loper 1999). Furthermore, different conditions may be required for the production of zoospores across many species. Therefore, the time to produce enough zoospores for use in a high-throughput assay may not be practical. However, mycelium is easily produced in culture by nonobligate oomycetes, and it is, therefore, widely applicable.

A mycelium-based method was developed at Clemson University, and it was utilized by Lookabaugh et al. (2015) and Olson et al. (2013) to assess fungicide sensitivity. This method is executed by visually rating the growth of oomycetes using an ordinal scale on fungicide-amended agar medium in 48-well 
microtiter plates (Olson et al. 2013). This method was modified by Huzar-Novakowiski and Dorrance (2018) to use liquid medium in 24-well microtiter plates with Pythium irregulare isolates. Although quicker than the amended medium method, the reliability and repeatability using visual assessment of mycelial growth could be improved by collecting objective quantitative OD data. It has been demonstrated that mycelium can be measured using OD with Phytophthora cinnamomi, Phytophthora multivora, and Phytophthora pluvialis (Hunter et al. 2018). In their study, Hunter et al. (2018) measured the growth of Phytophthora spp. by placing an inoculated agar plug into a 24-well plate, allowing the isolate to grow for a specified amount of time, reading OD at $620 \mathrm{~nm}$ at 32 positions within each well, and averaging the readings together to account for variation in growth within each well. An alternative method could be to use homogenized mycelium. Homogenized mycelial fragments could be added to liquid medium, allowed to grow, and then, quantified using a spectrophotometer. Kuhajek et al. (2003) suggested that growth in liquid culture from mycelial fragments of the genus Phytophthora might be too variable for a suitable assay because of coenocytic hyphae having inconsistent viability. However, quality controls can be used to identify unacceptable levels of variation. Methods like enzyme-linked immunosorbent assays, quantitative PCR, or ribonucleic acid interference (RNAi) screens administer quality control thresholds that identify and eliminate substandard data to reduce false positive rates (Birmingham et al. 2009; Schaad and Frederick 2002; Sutula et al. 1986). High-throughput drug screening assays for pharmaceutical purposes undergo rigorous testing, which must meet quality control benchmarks before implementation (Hughes et al. 2011).

In dose-response analysis of filamentous organisms, three factors should be considered for accurate determination of an $\mathrm{EC}_{50}$ estimation other than appropriate fungicide concentration selection. These factors include (i) low variability between technical well replicates and individual experiments, (ii) large measured differences in mycelial growth response between low and high concentrations (Sebaugh 2011), and (iii) that the mycelial growth measurement must be recorded while the organism is actively growing within the well to allow the response (OD) at each fungicide concentration to be measured and compared with the nonamended control. These factors are not easy to visually assess in 96-well microtiter plates because of the small volume of liquid medium in which isolates grow. This presents a quality and reproducibility challenge if appropriate quality controls are not implemented and could lead to erroneous results.

Two quality control measures were introduced in this study to address the three factors described above. First, we conducted growth curves for each isolate to ensure active growth at the time of measurement (i.e., linear to early $\log$ phase). Second, use of $Z^{\prime}$ factor (Zhang et al. 1999) assures that growth is consistent across wells and reliably greater than background noise (herein referred to as the negative control; i.e., OD of liquid medium without mycelium). $Z^{\prime}$ factor is sensitive to factors that affect either the dynamic range or variation in measured signal between positive and negative controls. Consequently, $Z^{\prime}$ factor is a good way to determine the robustness and reproducibility of fungicide sensitivity assays, and it is essential to standardize individual experiments. $Z^{\prime}$ factor is unitless and ranges from $-\infty$ to 1 , but a score of 1 is practically impossible, because this score can only be obtained if the difference in mean is $+\infty$ and the variation is equal to 0 . Zhang et al. (1999) interpreted $Z^{\prime}$ factors $>0.5$ as excellent, meaning that there is large difference between means and low variability. This cutoff has since become de facto for many assays, with the exception of phenotypic RNAi and image-based screening assays, where biologically relevant results are obtained with $Z^{\prime}$-factor scores $<0.5$ threshold (Buchser et al. 2012; Martin et al. 2012). Hughes et al. (2011) considered scores $>0.4$ acceptable but also, mentioned that scores $>0.5$ were preferred to further reduce false positives.
Therefore, the objectives of this study were to (i) develop a highthroughput microtiter plate-based fungicide sensitivity screening assay, (ii) implement growth curves and $Z^{\prime}$ factor for quality control, (iii) validate the high-throughput assay by comparing the sensitivity of oomycete species obtained using the high-throughput assay with those obtained with the amended medium assay, and (iv) demonstrate the utility of the high-throughput assay by testing the sensitivity to mefenoxam and ethaboxam of 81 oomycete species isolated from corn and soybean plants. We hypothesized that an assay using homogenized mycelial fragments as an inoculum source combined with the utilization of growth curves and $Z^{\prime}$ factor for quality control would permit screening hundreds of isolates across many oomycete species to multiple fungicides quickly in a robust manner.

\section{MATERIALS AND METHODS}

Oomycete isolates. In 2011 and 2012, >3,500 isolates representing five genera and 84 species of oomycetes were collected from soybean roots from 12 major soybean-producing states across the Midwest by collaborators of a U.S. Department of Agriculture-National Institute of Food and Agriculture Oomycete Soybean Cooperative Agricultural Project (Rojas et al. 2017a, b). Briefly, isolates used in this study were recovered from symptomatic corn or soybean roots by placing diseased root tissue on cornmeal agar (CMA) medium amended with pentachloronitrobenzene at $50 \mathrm{mg} \mathrm{liter}^{-1}$, ampicillin at $250 \mathrm{mg}$ liter-1, rifampicin at $10 \mathrm{mg} \mathrm{liter}^{-1}$, pimaricin at $5 \mathrm{mg} \mathrm{liter}^{-1}$, and benomyl at $10 \mathrm{mg} \mathrm{liter}{ }^{-1}$ (PARPB) (Jeffers 1986). Pure cultures were obtained via hyphal tip isolation and identified by sequencing the ITS region of the ribosomal DNA. For long-term storage, isolates were kept on $10 \%$ potato carrot agar (PCA) slants in scintillation vials until use. A subset of the oomycete collection representing 214 isolates across 81 species was used in this study (Supplementary Table S1). Additionally, two Pythium isolates from poinsettia known to be resistant to mefenoxam $\left(\mathrm{EC}_{50} \geq 100\right.$ $\mu \mathrm{g} \mathrm{ml}^{-1}$ ) (Del Castillo Múnera and Hausbeck 2016) were used to determine if resistant isolates could be detected with the highthroughput assay and the amended medium assay.

Fungicides. Commercial-grade mefenoxam (Apron XL; Syngenta Crop Protection Inc.) was dissolved in $\mathrm{dH}_{2} \mathrm{O}$ and passed through a $0.22-\mu \mathrm{m}$ filter. Unless otherwise noted, mefenoxam sensitivity was evaluated at $0.0,0.01,0.1,0.5,1$, and $10 \mu \mathrm{g} \mathrm{ml}^{-1}$ in dilute V8 broth (dV8B: $82 \mathrm{ml}$ of V8 juice filtered through eight layers of cheesecloth, $0.5 \mathrm{~g}$ of $\mathrm{CaCO}_{3}$, and $918 \mathrm{ml}$ of distilled water); nonamended $\mathrm{dV} 8 \mathrm{~B}$ was used as the control. Technicalgrade ethaboxam (Valent U.S.A. Corporation) was dissolved in $99.5 \%$ acetone. Ethaboxam sensitivity was evaluated at $0.0,0.01$, $0.1,0.5,1,5$, and $20 \mu \mathrm{g} \mathrm{ml}^{-1}$ in $\mathrm{dV} 8 \mathrm{~B}$; $\mathrm{dV} 8 \mathrm{~B}$ containing $0.0995 \%$ $\mathrm{vol} / \mathrm{vol}$ acetone was used for the control.

Amended medium assay for comparison with highthroughput assay. A fungicide amended agar medium assay (i.e., the gold standard assay) was conducted by placing a 3.7-mmdiameter plug from the edge of a 2- to 5-day-old oomycete colony growing on CMA + PARPB mycelium side down onto the center of three $100-\times 15-\mathrm{mm}$ petri plates containing dilute V8 agar medium (dV8A) amended with mefenoxam or ethaboxam at each concentration mentioned previously. dV8A was made by filtering V8 juice through eight layers of cheesecloth and adding $82 \mathrm{ml}$ of filtrate to $918 \mathrm{ml}$ of $\mathrm{dH}_{2} \mathrm{O}$ plus $0.5 \mathrm{~g}$ of $\mathrm{CaCO}_{3}$ and $15 \mathrm{~g}$ of agar. The colony diameter was measured with digital calipers (Mitutoyo America Corp.) in two perpendicular directions and averaged. The plug diameter $(3.7 \mathrm{~mm}$ ) was subtracted from the colony diameter. Measurements were made on actively growing colonies. Percentage relative growth was calculated by dividing the mean colony diameter of an isolate by the mean colony diameter on the nonamended plate of the same isolate multiplied by 100 .

Mycelial fragments for use in the high-throughput assay. Cultures grown on CMA + PARPB were transferred to dilute 
semisolid potato carrot agar (dsPCA) medium. dsPCA medium was prepared from PCA concentrate, which consisted of $200 \mathrm{~g}$ each peeled and cubed potatoes and carrots boiled for $1 \mathrm{~h}$ in 1 liter of $\mathrm{dH}_{2} \mathrm{O}$ and then filtered through eight layers of cheesecloth. To clarify the medium, $25 \mathrm{ml}$ of the PCA filtrate was centrifuged at $1,000 \times g$ for $10 \mathrm{~min}$, and the supernatant added to $975 \mathrm{ml}$ of distilled water and $5 \mathrm{~g}$ of agar. Mycelial fragments were generated by passing six $16.5-\mathrm{mm}$ plugs from the edge of an actively growing culture measuring at least $40 \mathrm{~mm}$ in diameter ( 2 to 5 days old) grown on dsPCA through a 20-gauge needle attached to a $10-\mathrm{ml}$ syringe into a 5-ml conical tube (Fig. 1A). Culture macerate was homogenized by vortexing for $10 \mathrm{~s}$. About $3 \mathrm{ml}$ of the culture macerate was pipetted using wide orifice tips into eight-well reservoirs to facilitate distribution with a multichannel pipettor (Fig. 1A).

High-throughput assay execution. To assess the fungicide sensitivity of 216 isolates representing four oomycete genera and 81 species, $50 \mu \mathrm{l}$ of culture macerate was aliquoted from eightwell reservoirs using a multichannel pipettor with wide orifice tips in triplicate of each isolate into 96-well flat-bottom microtiter plates (Model 3620, Corning Inc.) preloaded with $200 \mu \mathrm{l}$ of dV8B in each well amended with the fungicide concentrations mentioned previously (Fig. 1B). dV8B was made in the same way as dV8A without agar. Therefore, the growth medium of the amended medium assay or the high-throughput assay was either dV8A or dV8B. Microtiter plates were incubated in the dark at $24^{\circ} \mathrm{C}$ for $48 \mathrm{~h}$ inside a covered plastic bin containing a beaker of water to prevent evaporation. The OD of each well was measured spectrophotometrically at $600 \mathrm{~nm}$ with a Tecan Safire plate reader (Tecan Group Ltd.) after 24 and $48 \mathrm{~h}$ to account for fast- and slowgrowing isolates. Wells containing noninoculated macerated agar with $\mathrm{dV} 8 \mathrm{~B}$ plus fungicide at the same concentrations mentioned previously were included as negative controls. The mean OD of the negative control was subtracted from the OD of wells containing a growing isolate. Wells containing an isolate of Pythium oopapillum (isolate 143) were used as a positive control in each 96-well plate. This isolate was sensitive to both mefenoxam and ethaboxam, and its noninhibited growth reached linear to early log-phase growth $\left(0.7\right.$ to $\left.0.8 \mathrm{OD}_{600}\right)$ after $24 \mathrm{~h}$ at $24^{\circ} \mathrm{C}$. Growth curves were generated by monitoring the OD of each isolate over 48 to $60 \mathrm{~h}$ in a 96-well plate containing nonamended V8B.

\section{A \\ Place plugs in top of syringe \\ Macerate by passing mycelial agar plugs through syringe and needle \\ $3 \mathrm{ml}$ macerate into reservoirs}

6, $16.5 \mathrm{~mm}$ plugs

From 2 - 5 day old cultures
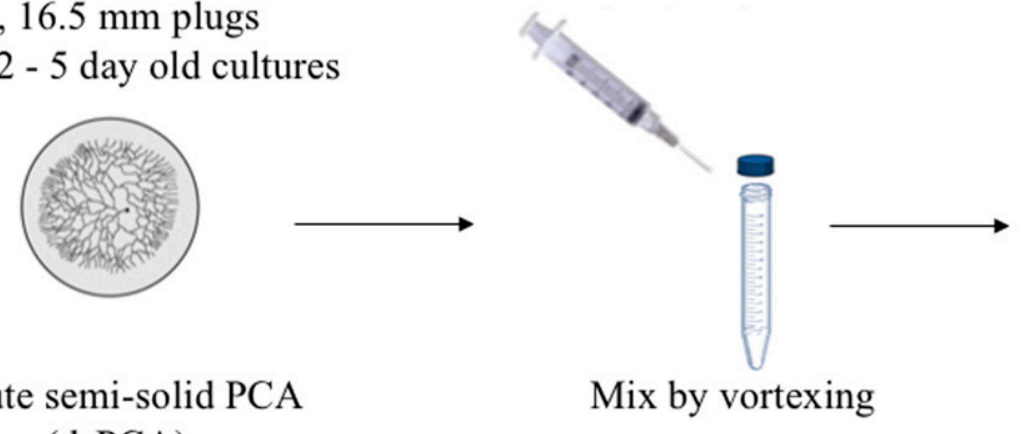

Dilute semi-solid PCA (dsPCA)

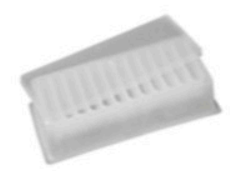

Reservoir 1

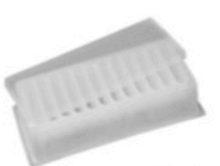

Reservoir 3

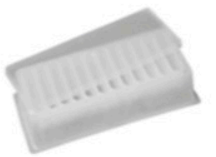

Reservoir 2

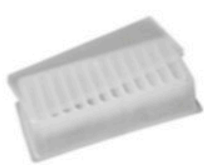

Reservoir 4

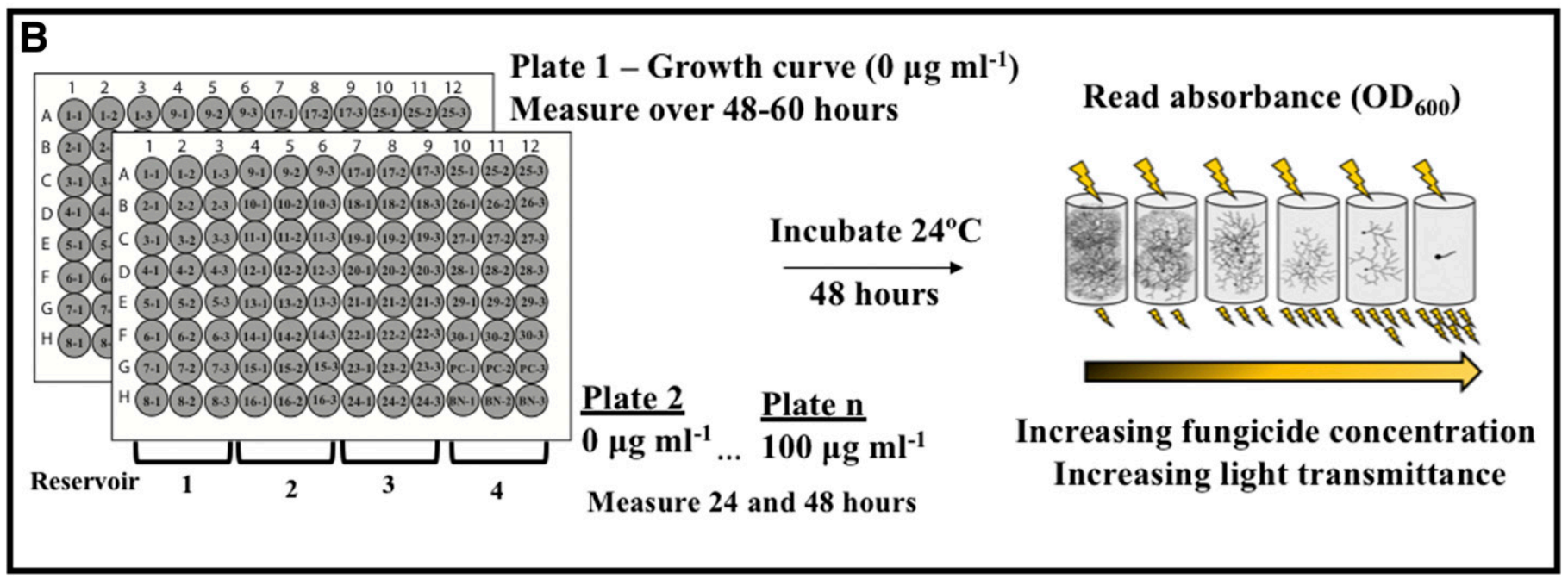

Fig. 1. The methodology of the high-throughput fungicide phenotyping assay. A, Oomycete isolates were grown on dilute semisolid potato carrot agar (dsPCA) medium. Six plugs from cultures were placed into the top of a 10-ml syringe and macerated by passing the culture through a 20-gauge needle into a 5-ml collection tube. Collection tubes containing macerate were vortexed to homogenize, and $3 \mathrm{ml}$ was pipetted using wide orifice tips into eight-well reservoirs. B, Fifty microliters of macerate was then pipetted using a multichannel pipettor with wide orifice tips into triplicate wells of preloaded 96-well plates containing $200 \mu 1$ of dilute V8 broth with desired fungicide concentrations (plate 2 - plate $n$ ). One plate contained no fungicide and was monitored over 48 to $60 \mathrm{~h}$ to generate growth curves for each isolate (plate 1). A positive control isolate was placed into wells G10 to G12 for every experiment. Noninoculated macerated agar (i.e., the negative control) was placed into wells $\mathrm{H} 10$ to $\mathrm{H} 12$. Microtiter plates were incubated at $24^{\circ} \mathrm{C}$ and measured at 24 and $48 \mathrm{~h}$ at $600 \mathrm{~nm}$ (optical density at $600 \mathrm{~nm}$ [OD 600$]$ ). The mean OD of the negative control was subtracted from the OD of each isolate. 
Percentage relative growth of each isolate was calculated by dividing the mean OD of the mycelia at each fungicide concentration by the mean OD of mycelia in nonfungicide-amended medium multiplied by 100 . A single fungicide concentration was used per 96-well plate, with a maximum of 30 isolates in a plate. $\mathrm{EC}_{50}$ values were reported as $\mathrm{EC}_{50}$ distributions to examine the range in interspecific responses to ethaboxam or mefenoxam. Each isolate was repeated at least once, with at least $24 \mathrm{~h}$ separating each biological replicate.

Quality control within the high-throughput assay. The following quality controls were set for $\mathrm{EC}_{50}$ estimation: (i) growth (i.e., OD) was considered distinguishable from the negative control according to a $Z^{\prime}$ factor $>0.4$ (Hughes et al. 2011), and (ii) the isolate was actively growing (i.e., linear to early log phase) (Fig. 2). For each isolate, $Z^{\prime}$ factor was calculated using the following formula:

$$
Z^{\prime} \text { factor }=1-\frac{3\left(\sigma_{p}+\sigma_{n}\right)}{\left|\mu_{p}-\mu_{n}\right|}
$$

where $Z^{\prime}$ factor equals one minus three times the sum of the standard deviation of the OD of the nonamended $\left(\sigma_{p}\right)$ and standard deviation of the negative control $\left(\sigma_{n}\right)$ divided by the absolute difference of the mean OD of the nonamended $\left(\mu_{\mathrm{p}}\right)$ and mean of the negative control $\left(\mu_{\mathrm{n}}\right) . Z^{\prime}$ factor was estimated at 24 and $48 \mathrm{~h}$. Statistical power was calculated for $Z^{\prime}$ factor according to Sui and $\mathrm{Wu}$ (2007). Growth curve data were assessed visually to confirm that the isolates were actively growing (i.e., linear or late log phase) at the time of $\mathrm{EC}_{50}$ estimation.

Evaluation of reliability and reproducibility of the highthroughput assay with $Z^{\prime}$ factor. $Z^{\prime}$ factor was also used to assess the suitability of the high-throughput assay to determine if conditions allowed active growth to be consistently distinguished from inhibited growth or the negative control. The experimental workflow outlined by Chai et al. (2015) was adopted. Macerate was generated from the positive control isolate and noninoculated agar. Fifty microliters of macerate was aliquoted into eightwells within columns of a 96-well plate, resulting in the following treatments: (i) the positive control isolate grown in nonfungicideamended V8B (noninhibited growth), (ii) the positive control isolate with either $10 \mu \mathrm{g} \mathrm{ml}^{-1}$ of mefenoxam- or $20 \mu \mathrm{g} \mathrm{ml}^{-1}$ of ethaboxam-amended V8B (inhibited growth), or (iii) noninoculated macerate without fungicide-amended V8B (Supplementary Fig. S1). These treatments were aliquoted across three 96-well plates on the same day, and treatments were varied across columns in a 96-well plate. For example, plate 1 contained treatment 1 (noninhibited growth) in all wells of columns 1, 4, 7, and 10; treatment 2 (inhibited growth) was located in all wells of columns $2,5,8$, and 11; and treatment 3 was located in all wells of columns $3,6,9$, and 12 . For plates 2 and 3 , the positions of treatments within 96-well plates were varied by column so that they did not match plate 1 . This experimental setup was repeated over 3 consecutive days. The difference in means of OD and $Z^{\prime}$ factor was calculated to compare all treatments across multiple wells within the same 96-well plate, across multiple 96-well plates on the same day, and across multiple 96-well plates on different days.

Inter- and intraspecific validation of high-throughput assay by comparison with the amended medium assay. Relative growth and $\mathrm{EC}_{50}$ values obtained using the highthroughput assay were compared with those obtained with the fungicide-amended medium method. These data were compared inter- and intraspecifically. For the interspecific comparison, $\mathrm{EC}_{50}$ values and relative growth values of 30 isolates representing 12 species of the genera Pythium and Phytophthora were evaluated using ethaboxam, and 24 isolates representing 11 species of the genera Pythium, Phytophthora, and Phytopythium were tested using mefenoxam. The two isolates resistant to mefenoxam (isolates 101 and 207) were evaluated at the previously mentioned concentrations and $100 \mu \mathrm{g} \mathrm{ml}^{-1}$ to confirm that they were resistant using the high-throughput and amended medium assays. The

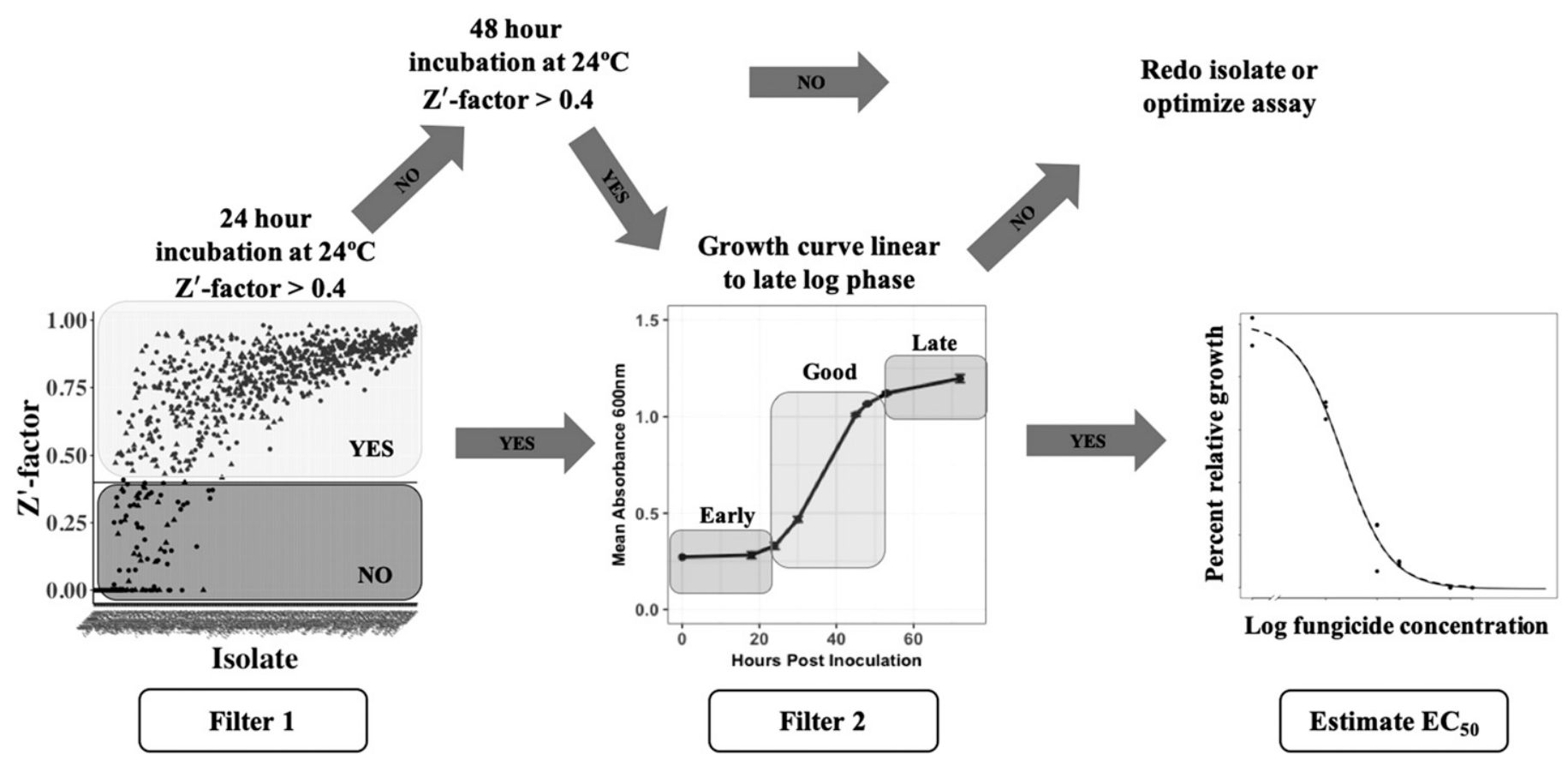

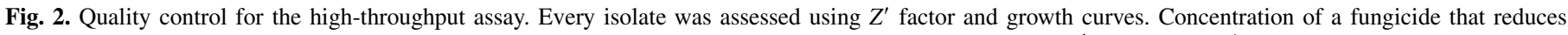

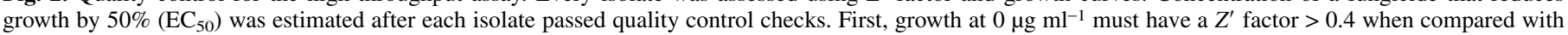

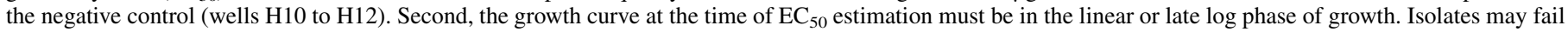

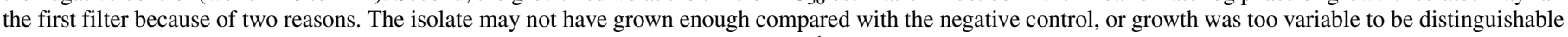

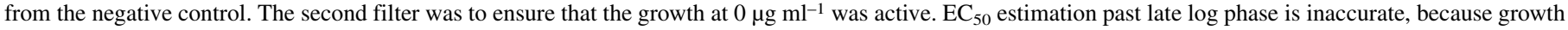
in the presence of fungicide may not be lethal but rather, may be slow, thus making the isolate appear more insensitive. 
assay comparison with ethaboxam included isolates with $\mathrm{EC}_{50}$ values ranging from 0.016 to $>20 \mu \mathrm{g} \mathrm{ml}^{-1}$. For the intraspecific comparison, we used 27 isolates of Pythium oopapillum tested using mefenoxam at $0.0,0.01,0.05,0.1,0.5$, and $1 \mu \mathrm{g} \mathrm{ml}^{-1}$.

Statistical analyses. All statistical analyses were conducted using R v.3.43 (R Core Team 2017). The percentage relative growth was plotted against log-transformed fungicide concentration and modeled using a four-parameter log-logistic curve. $\mathrm{EC}_{50}$ values were estimated from this model by solving for the point where $50 \%$ relative growth occurred (absolute $\mathrm{EC}_{50}$ ) by specifying type equal to "absolute" in the "ED" function of the R package drc (Noel et al. 2018; Ritz and Streibig 2005; Sebaugh 2011). $Z^{\prime}$ factor was calculated using custom functions and scripts. The experimental design was a complete randomized design with at least two biological replicates. Analysis of variance was used to test if the method (i.e., amended medium assay or high-throughput assay) resulted in different $\mathrm{EC}_{50}$ or relative growth distributions. Linear regression analysis was used to determine if the slope $(\beta)$ and $y$ intercept of the linear models comparing $\mathrm{EC}_{50}$ values were different from a theoretical 1:1 relationship by comparing the terms with one and zero, respectively, using $t$ tests (Förster et al. 2004). Linear regression analysis was carried out with the packages lme4 (Bates et al. 2015) and lsmeans (Lenth 2016). In addition to linear regression analysis, concordance correlation coefficient (Lin 1989) was used to evaluate the accuracy and precision of the highthroughput assay. Spearman's correlation was used to determine if $\mathrm{EC}_{50}$ or relative growth values obtained using the high-throughput or amended medium assays were correlated. All data, functions, and analyses can be downloaded at https://github.com/noelzach/Community_Fungicide_Sensitivity.

\section{RESULTS}

Evaluation of reliability and reproducibility of the highthroughput assay with $Z^{\prime}$ factor. $Z^{\prime}$ factor was used to assess well-to-well, plate-to-plate, and day-to-day variability in OD for both ethaboxam and mefenoxam (Supplementary Table S2). Comparing the noninhibited growth with the negative control or comparing the inhibited growth with ethaboxam, the well-to-well, plate-to-plate, and day-to-day $Z^{\prime}$-factor scores were all $>0.60$. Similar results were obtained when the same comparison was made with mefenoxam, which resulted in a $Z^{\prime}$ factor $>0.56$. Among the two chemistries evaluated, only the $Z^{\prime}$-factor scores comparing the negative control with inhibited growth were $<0$ as expected.

Quality control with $Z^{\prime}$-factor filtering and growth curves. The high-throughput assay allowed data collection of $82 \%$ of the 218 isolates screened at $24 \mathrm{~h}$ postinoculation (mean growth rate $=0.28$ OD units per hour) and $18 \%$ of isolates at $48 \mathrm{~h}$ postinoculation (mean growth rate $=0.16 \mathrm{OD}$ units per hour). Of the isolates measured after $24 \mathrm{~h}$, on average $87.5 \%$ passed the $Z^{\prime}$-factor quality control filter after the first trial. The isolates that did not pass were repeated until all isolates passed. The power of a $Z^{\prime}$ factor $>0.4$ to indicate that the mean of the noninhibited growth was at least three standard deviations away from the negative control was 100\% for all isolates tested (Supplementary Fig. S2).

As examples of quality control (Fig. 2), data from two isolates (isolates 82 and 75) are shown (Fig. 3). For isolate 82, $Z^{\prime}$-factor filtering was able to identify that this isolate required a longer (i.e., $48 \mathrm{~h}$ ) growth period to be distinguished from the negative control. For example, $Z^{\prime}$ factor after $24 \mathrm{~h}$ of growth was $<0.4$, but after $48 \mathrm{~h}$, it was $>0.4$ (Fig. 3A). The growth curve was in the linear phase at $48 \mathrm{~h}$, indicating that the isolate was actively growing after $48 \mathrm{~h}$. Estimating $\mathrm{EC}_{50}$ at $24 \mathrm{~h}$ resulted in the lower parameter of the dose-response curve not being $<50 \%$, indicating that an absolute $\mathrm{EC}_{50}$ was undefined and thus, making the isolate seem insensitive (Fig. 3B). However, estimation of the $\mathrm{EC}_{50}$ at $48 \mathrm{~h}$ resulted in a defined absolute $\mathrm{EC}_{50}$. For isolate 75 , growth at $24 \mathrm{~h}$ was in the linear phase, but the $Z^{\prime}$ factor was $<0.4$ (Fig. 3C). When repeating isolate 75 for a second trial, the $Z^{\prime}$ factor was $>0.4$ after $24 \mathrm{~h}$ of growth and resulted in a lower $\mathrm{EC}_{50}$ estimation (Fig. 3D).

Interspecific validation of high-throughput assay. There were significant correlations and linear relationships between $\mathrm{EC}_{50}$ values and percentage relative growth values at all concentrations of ethaboxam and mefenoxam (Fig. 4 and Supplementary Table S3). The adjusted coefficients of determination $\left(R^{2} a d j\right)$ for linear models comparing $\mathrm{EC}_{50}$ and percentage relative growth at $0.5 \mu \mathrm{g} \mathrm{ml}^{-1}$ were 0.53 and 0.84 , respectively, for ethaboxam and 0.86 and 0.87 , respectively, for mefenoxam. The slope $(\beta)$ and $y$ intercept of the linear model comparing ethaboxam $\mathrm{EC}_{50}$ values were not significantly different from zero and one, respectively $(P=0.493$ and 0.335 , respectively), but they were significantly different for the linear model comparing percentage relative growth at $0.5 \mu \mathrm{g} \mathrm{ml}^{-1}(P=0.010$ and $P<0.001$, respectively). Evaluating mefenoxam, the slope $(\beta)$ of the linear model comparing $\mathrm{EC}_{50}$ values and percentage relative growth at $0.5 \mu \mathrm{g}$ $\mathrm{ml}^{-1}$ was significantly different than one $(P=0.017$ and 0.044 , respectively), but the $y$ intercept was not significantly different from zero $(P=0.317$ and 0.133 , respectively). Spearman correlation coefficients for ethaboxam and mefenoxam were 0.84 and 0.74 ( $\mathrm{EC}_{50}$ values), respectively, and 0.87 and 0.67 (percentage relative growth), respectively. Lin's concordance correlation coefficients $(\rho)$ comparing $\mathrm{EC}_{50}$ and percentage relative growth at 0.5 $\mu \mathrm{g} \mathrm{ml}^{-1}$ were 0.73 and 0.89 , respectively, for ethaboxam and 0.73 and 0.95 , respectively, for mefenoxam (Fig. 5). The accuracies $\left(C_{\beta}\right)$ comparing $\mathrm{EC}_{50}$ and percentage relative growth at $0.5 \mu \mathrm{g} \mathrm{ml}^{-1}$ were 0.98 and 0.96, respectively, for ethaboxam and 0.84 and 0.99, respectively, for mefenoxam (Fig. 5). The mean $\mathrm{EC}_{50}$ was significantly different between isolates $(P<0.001)$, chemistry $(P<$ $0.001)$, and isolate chemistry interaction $(P<0.01)$, but it was not significantly different for any isolate, chemistry, and method interaction $(P=0.85)$ (Table 1$)$. Isolates with resistance to mefenoxam in the amended medium method were also resistant in the high-throughput assay, with mean percentage relative growth values $>75 \%$ at $100 \mu \mathrm{g} \mathrm{ml}-1$. Isolates with insensitivity to ethaboxam $\left(\mathrm{EC}_{50} \geq 20 \mu \mathrm{g} \mathrm{ml}^{-1}\right)$ in the amended medium method were also insensitive in the high-throughput assay, with mean percentage relative growth values $>75 \%$ at $20 \mu \mathrm{g} \mathrm{ml}^{-1}$.

Intraspecific validation of high-throughput assay. There was a significant correlation and a significant linear relationship between $\mathrm{EC}_{50}$ values for 27 Pythium oopapillum isolates challenged against mefenoxam (Fig. 5). The slope of the $\mathrm{EC}_{50}$ linear model was significantly different from one $(P=0.002)$, but the $y$ intercept was not significantly different from zero $(P=0.062)$ (Supplementary Table S4), and the $R_{a d j}^{2}$ for the $\mathrm{EC}_{50}$ linear model was 0.28 (Fig. 5A). Lin's concordance correlation coefficient $(\rho)$ was 0.50 , and accuracy $\left(C_{\beta}\right)$ was 0.90 (Fig. $5 \mathrm{~A}$ ). There was no significant difference in mean $\mathrm{EC}_{50}$ values between the highthroughput and amended medium assays (Fig. 5B). There was a significant linear relationship $(P=0.004)$ and a significant Spearman correlation $(P=0.041)$ between relative growth values at $0.1 \mu \mathrm{g} \mathrm{ml}^{-1}$ but not at other concentrations. There were no significant differences in mean percentage relative growth at 0.01 , $0.05,0.1$, and $0.5 \mu \mathrm{g} \mathrm{ml}^{-1}$, but mean percentage relative growth at $1 \mu \mathrm{g} \mathrm{ml}^{-1}$ was significantly greater $(P=0.012)$ with the highthroughput assay compared with the amended medium (Fig. 5C).

Variation in interspecific sensitivity of corn and soybean isolates to mefenoxam and ethaboxam. About two-thirds $(65 \%)$ of the isolates tested with ethaboxam had an $\mathrm{EC}_{50}<1 \mu \mathrm{g} \mathrm{ml}^{-1}$, whereas $20 \%$ had $\mathrm{EC}_{50}$ values between 1 and $5 \mu \mathrm{g} \mathrm{ml}^{-1}$ of ethaboxam (Fig. 6A). Two isolates belonging to Pythium catenulatum had $\mathrm{EC}_{50}$ between 11 and $20 \mu \mathrm{g} \mathrm{ml}^{-1}$ of ethaboxam. Isolates with $\mathrm{EC}_{50}>20 \mu \mathrm{g} \mathrm{ml}^{-1}$ belonged to species Pythium acrogynum, Pythium aphanidermatum, Pythium camurandrum, Pythium carolinianum, Pythium hypogynum, Pythium aff. hypogynum, Pythium longandrum, Pythium longisporangium, Pythium torulosum, Pythium aff. torulosum, and Pythium rostratifingens. For mefenoxam, 92\% isolates had 
an $\mathrm{EC}_{50}$ between 0.01 and $0.5 \mu \mathrm{g} \mathrm{ml}^{-1}$ (Fig. 6B). Phytopythium litorale and Phytopythium sterilum had mean $\mathrm{EC}_{50}$ values $>0.5$ $\mu \mathrm{g} \mathrm{ml}-1$, and the only representative isolate of Phytopythium megacarpum tested had an $\mathrm{EC}_{50}>10 \mu \mathrm{g} \mathrm{ml}^{-1}$ of mefenoxam.

\section{DISCUSSION}

The primary objective of this study was to develop and validate a high-throughput assay for oomycete fungicide sensitivity that implemented quality controls. Utilizing mycelial fragments enabled the use of this assay across 81 oomycete species. Adoption of mycelial fragments is an essential improvement from a previous microtiter method for oomycetes, which demonstrated zoospores as an inoculum source on a small set of Phytophthora spp. (Kuhajek et al. 2003). Furthermore, the maceration technique enabled the use of a multichannel pipette and 96-well microtiter plates, improving throughput compared with the use of culture plugs and larger-well microtiter plates. Additionally, the maceration method could be used to generate mycelial fragments for any nonobligate oomycete, not just those tested in this study. Additionally, objective spectrophotometric quantification of mycelial growth from homogenized mycelial fragments eliminated issues posed by subjective scoring and ordinal data (HuzarNovakowiski and Dorrance 2018; Lookabaugh et al. 2015; Olson et al. 2013). Finally, robust quality controls were implemented to ensure that generated data were sound. The combined utilization of growth curves and $Z^{\prime}$ factor has not been previously applied in highthroughput fungicide sensitivity methods in the phytopathology literature.

Because of these improvements, the presented framework addresses the four FRAC-defined requirements for fungicide microbioassays. (i) The assay was demonstrated to be robust, reliable, and repeatable by utilizing $Z^{\prime}$ factor. (ii) The method is quick and easy to apply to many species, because it does not rely on the production of zoospores. We estimate the high-throughput assay to be at least four times quicker to perform than the amended
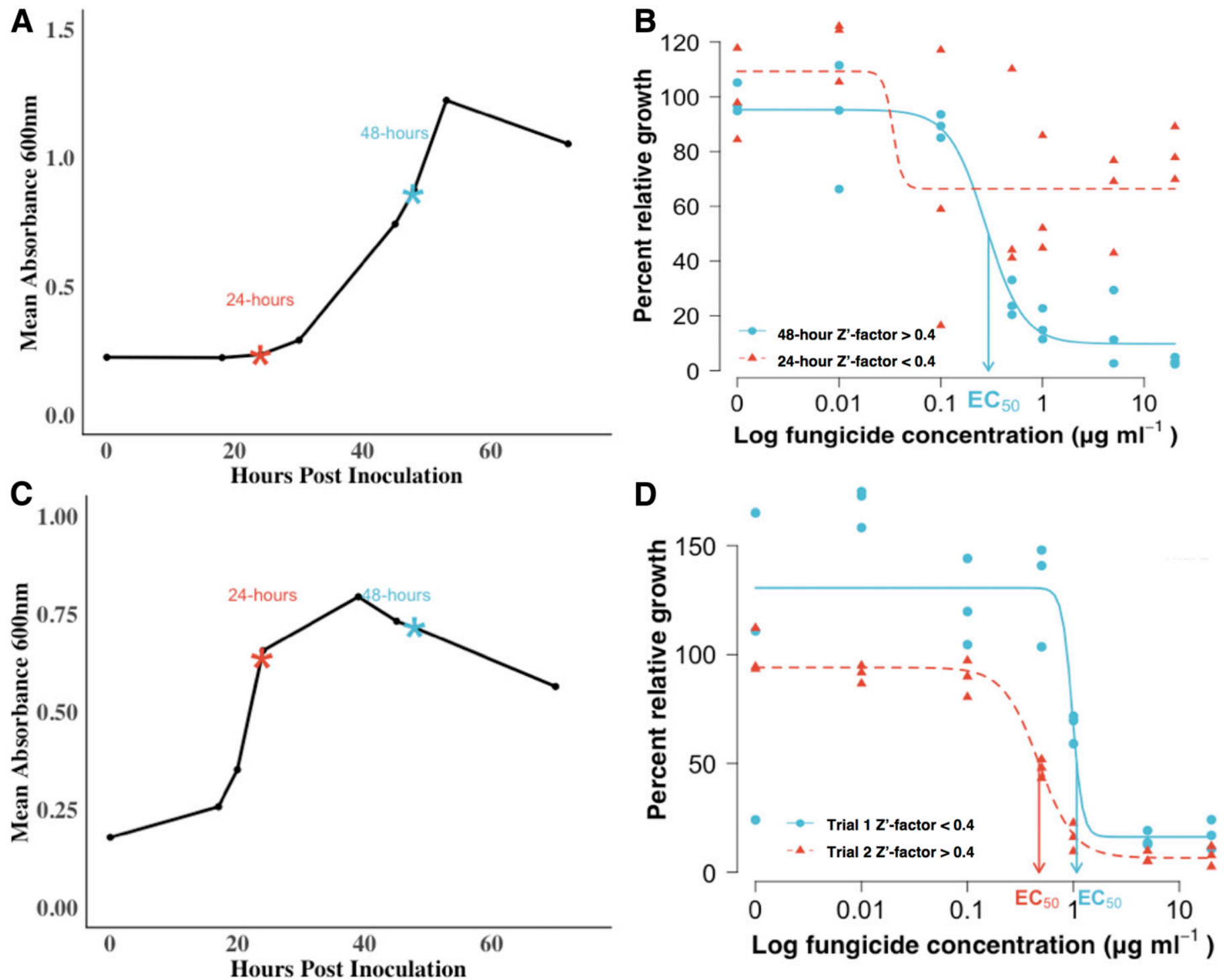

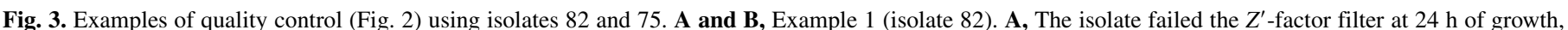

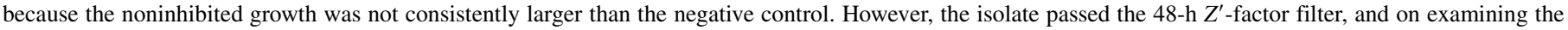

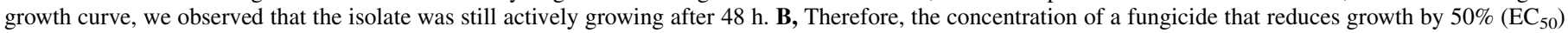

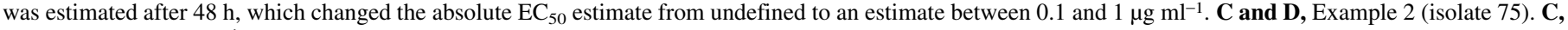

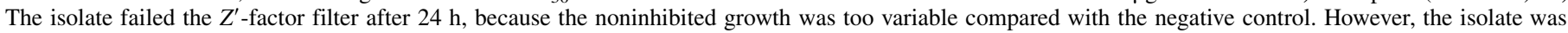

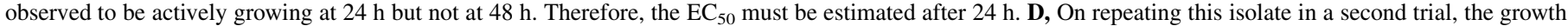
was more consistent and passed the $Z^{\prime}$ factor after $24 \mathrm{~h}$, which reduced the $\mathrm{EC}_{50}$ estimate from $>1$ to $<1 \mu \mathrm{g} \mathrm{ml}^{-1}$. 
medium method. For example, maceration and inoculation of microtiter plates of 30 isolates at seven concentrations of two fungicides were completed in under $4 \mathrm{~h}$, replacing the need for medium pouring, plug inoculation, and measurement of 1,344 petri plates. Measurement of microtiter plates takes minutes on a spectrophotometer rather than hours of measuring individual colony diameters. (iii) The method is cheap, saving labor and material costs. We estimate the cost, assuming labor costs of $\$ 9$ to $12 / \mathrm{h}$, of screening from $\sim \$ 12$ per isolate using the amended medium method to $\$ 4$ per isolate using the high-throughput assay. Furthermore, because the high-throughput assay can correctly distinguish resistant and sensitive isolates, the results can be related to field sensitivity. However, additional studies are needed to relate specific isolates and sensitivity to field resistance.

The high-throughput method was designed to apply to many oomycete species; however, optimal wavelengths or medium types could vary by species. Six hundred nanometers were used because this wavelength is typically used to quantify microbial suspensions and close to the $620 \mathrm{~nm}$ used by Kuhajek et al. (2003). A synthetic medium instead of dV8B may provide lower OD readings within the negative control, which may generate higher $Z^{\prime}$-factor scores. In fact, Kuhajek et al. (2003) demonstrated that growth from
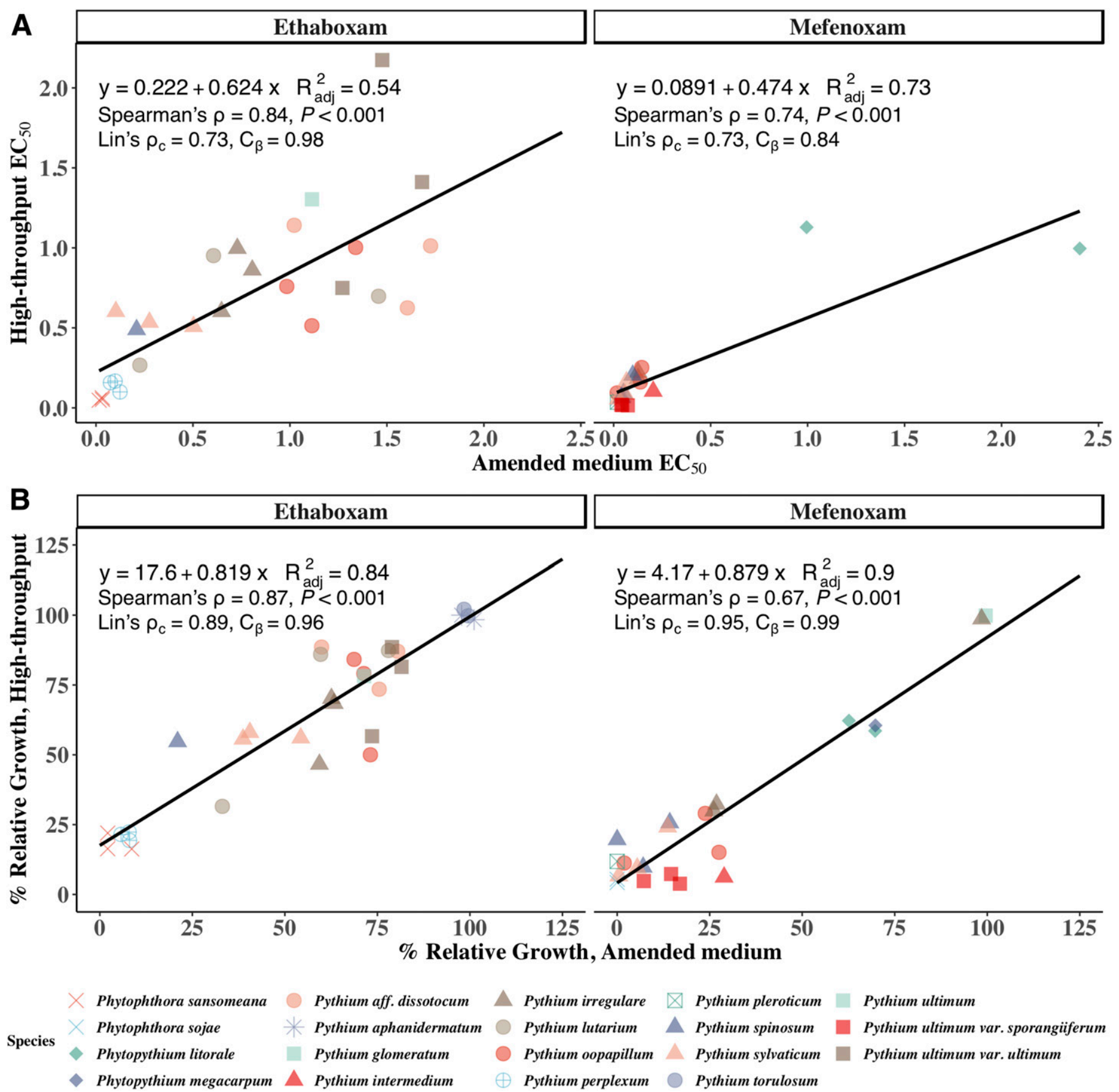

$R_{\text {adj }}^{2}=0.84$

Spearman's $\rho=0.87, P<0.001$ s

\section{A}


zoospores of Phytophthora nicotianae was superior in $\mathrm{dV} 8 \mathrm{~B}$, but they decided to use a synthetic medium to be more repeatable. It was uncertain if this synthetic medium would have been suitable for all species tested in this study. Therefore, we utilized dV8B, because it is known to allow quick, reliable growth of oomycetes (Luo et al. 1988; Zelaya-Molina et al. 2011). Furthermore, using the same growth medium in the amended medium and high-throughput assays enabled a side-by-side comparison. Although it should be noted that the sensitivity of zoospores can be different from mycelium, the use of mycelium fragments allows for the testing of a wide range of oomycete isolates and species in which zoospore production may be difficult (Garbelotto et al. 2009). However, the appropriateness of mycelial fragments may depend on the fungicide used, because the activity of the fungicide may depend on the developmental stage (Cohen and Gisi 2007).

The use of the $Z^{\prime}$-factor statistic was useful for developing the high-throughput assay for two reasons. First, it was used as a datafiltering statistic in the data processing workflow (Fig. 2). Second, it was useful for assessing the reliability and reproducibility of high-throughput assay conditions across multiple wells, plates, and days. A $Z^{\prime}$-factor cutoff of $>0.4$ was selected, because this threshold has been successfully used in assays involving phenotypic responses (Buchser et al. 2012; Hughes et al. 2011; Martin et al. 2012). A $Z^{\prime}$ factor of 0.4 instead of the de facto 0.5 threshold still enabled considerable power to distinguish growth from the negative control, despite the lower threshold. However, future studies should pay attention to this threshold and ensure enough power to detect true differences (Sui and Wu 2007). Using $Z^{\prime}$ factor as a quality control filtering statistic allowed the identification of isolates that did not grow sufficiently compared with the negative control or when growth without fungicide was too variable (Fig. 3). On repeating isolates with $Z^{\prime}$ factor $<0.4$, we were able to make more accurate $\mathrm{EC}_{50}$ estimations (Fig. 3). Perhaps this variation was caused by pipetting errors causing unequal distribution of mycelial fragments in wells or unequal viability of mycelial fragments as alluded to by Kuhajek et al. (2003).

In some cases, isolates of species with particularly slow and variable growth, like Phytophthora sojae, were more difficult to obtain acceptable $Z^{\prime}$-factor scores for. If desired, the conditions of the high-throughput assay could be optimized further for Phytophthora sojae or any other species by varying the conditions presented herein. For example, Kuhajek et al. (2003) used $620 \mathrm{~nm}$ for Phytophthora nicotianae, and multiple medium types were tested. Replicating the reliability and reproducibility experiment with Phytophthora sojae could help improve the high-throughput

TABLE 1. Analysis of variance table for the concentration of a fungicide that reduces growth by $50 \%$ for each isolate and chemistry

\begin{tabular}{|c|c|c|c|c|c|}
\hline Factor & $\mathrm{df}^{\mathrm{a}}$ & $\mathrm{SS}^{\mathrm{b}}$ & $\mathrm{MS}^{\mathrm{c}}$ & $F$ value & $P$ value \\
\hline Isolate & 37 & 360.33 & 9.74 & 17.68 & $<0.0001$ \\
\hline Chemistry $^{\mathrm{d}}$ & 1 & 69.51 & 69.51 & 126.20 & $<0.0001$ \\
\hline Methode $^{\mathrm{e}}$ & 1 & 0.72 & 0.72 & 1.30 & 0.26 \\
\hline Isolate $\times$ chemistry & 7 & 11.59 & 1.66 & 3.01 & $<0.01$ \\
\hline Isolate $\times$ method & 37 & 19.05 & 0.52 & 0.93 & 0.58 \\
\hline Chemistry $\times$ method & 1 & 0.74 & 0.74 & 1.34 & 0.25 \\
\hline Isolate $\times$ chemistry $\times$ method & 7 & 1.81 & 0.26 & 0.47 & 0.85 \\
\hline Error & 120 & 66.09 & 0.55 & - & - \\
\hline Total & 211 & 529.84 & - & - & - \\
\hline
\end{tabular}

a $\mathrm{df}=$ degrees of freedom.

b $\mathrm{SS}=$ sum-of-squares.

c $\mathrm{MS}=$ mean squares.

d Ethaboxam and mefenoxam.

e High-throughput or (gold standard) amended medium.
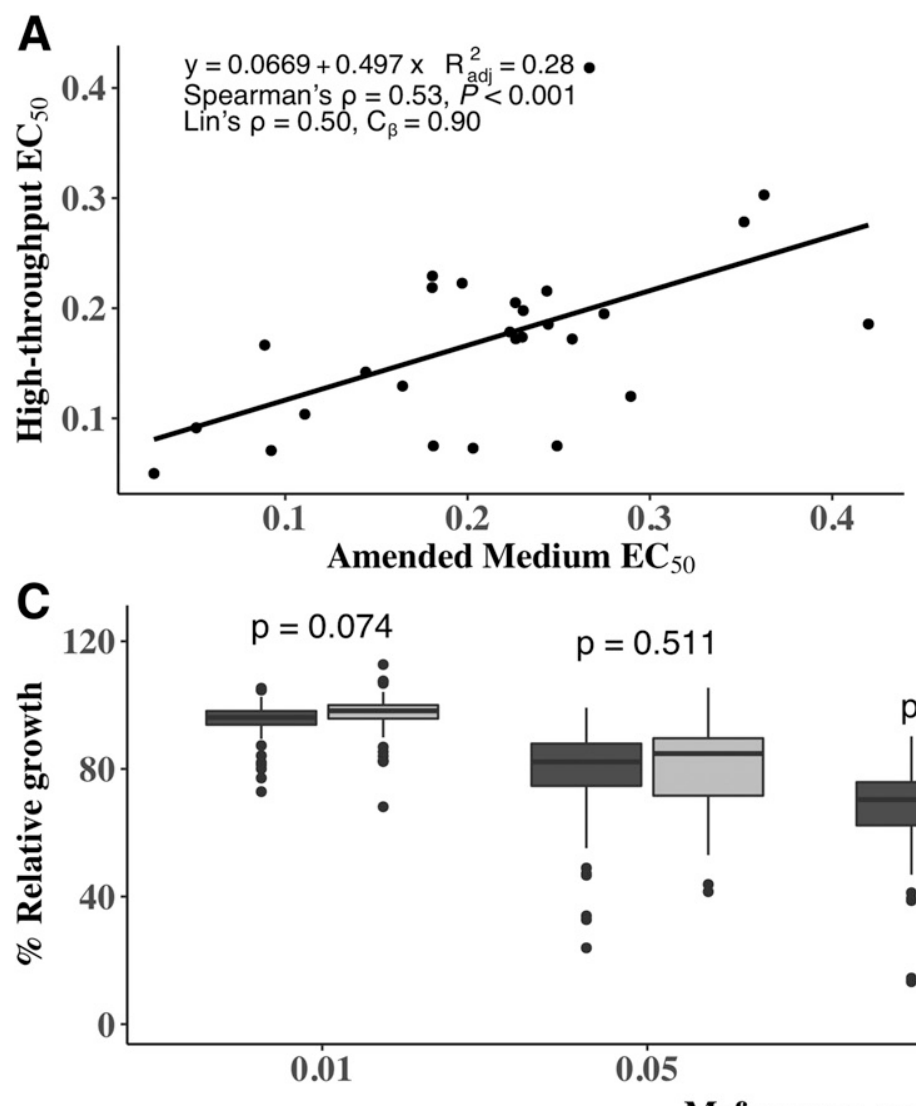

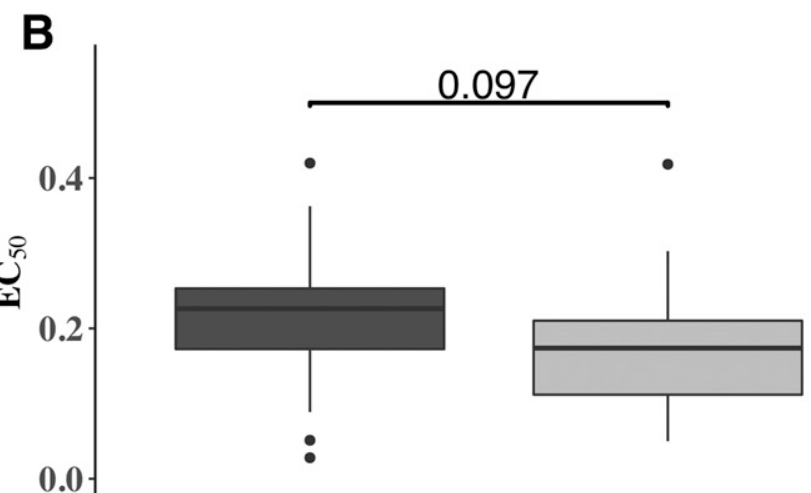

Amended Medium
High-throughput

\section{Method

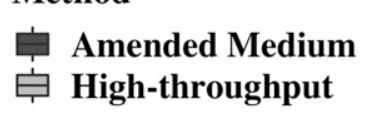

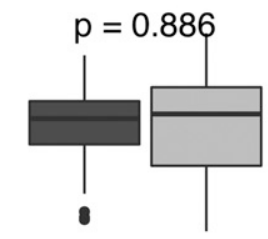

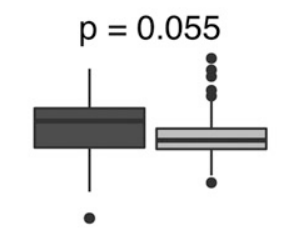

0.1
0.5

Mefenoxam concentration $\left(\mu \mathrm{g} \mathrm{ml}^{-1}\right)$

Fig. 5. High-throughput assay comparison with the (gold standard) amended medium assay using 27 isolates of Pythium oopapillum challenged against mefenoxam. A, Linear model and correlation analysis of concentration of a fungicide that reduces growth by $50 \%$ (EC 50 ) values. B, Comparison of mefenoxam $\mathrm{EC}_{50}$ distributions. $\mathbf{C}$, Comparison of relative growth distributions at five concentrations of mefenoxam. 


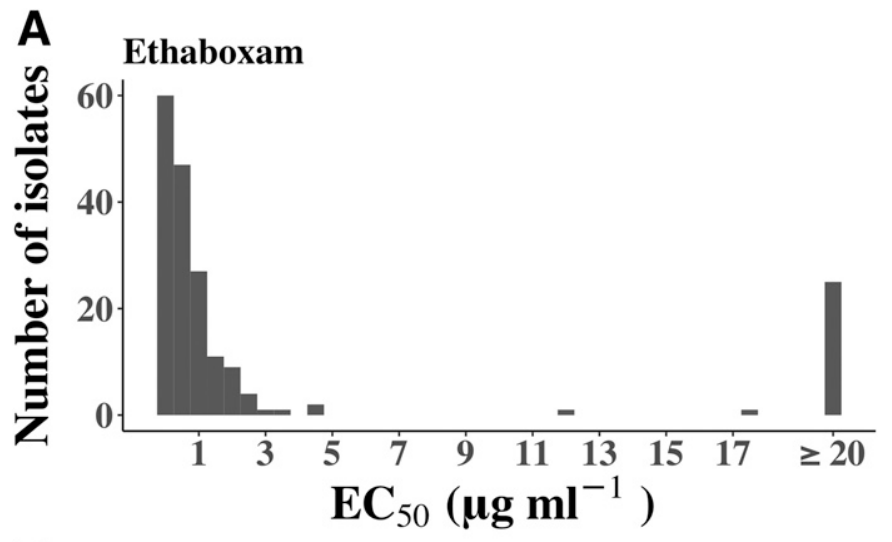

B

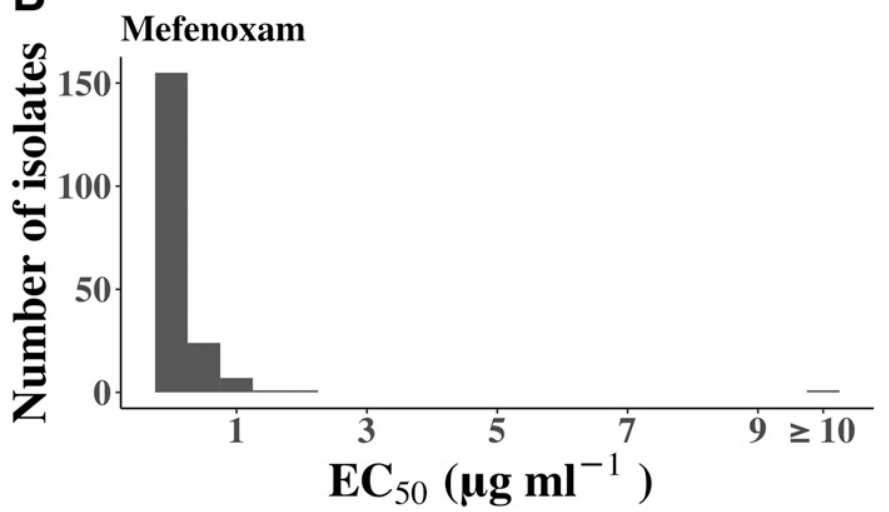

Fig. 6. Demonstration of the utility of the high-throughput assay to generate concentration of a fungicide that reduces growth by $50 \%\left(\mathrm{EC}_{50}\right)$ values of soybean and corn isolates representing four genera and 81 oomycete species. Distributions represent the mean $\mathrm{EC}_{50}$ for at least two biological replicates for each isolate challenged against $\mathbf{A}$, ethaboxam and $\mathbf{B}$, mefenoxam. $\mathrm{EC}_{50}$ values were estimated with a four-parameter log-logistic model from dose-response data from seven fungicide concentrations for each chemistry tested. These data would represent the equivalent data of $>16,000$ petri plates if this experiment was performed using the (gold standard) amended medium method.

assay by optimizing the conditions of the assay that allow for acceptable $Z^{\prime}$-factor scores. Additionally, the reliability and reproducibility experiment could be repeated across laboratories to validate conditions before screening hundreds of isolates as was done in this study.

The accuracy and precision of the high-throughput assay were assessed with linear regression analysis and Lin's concordance correlation comparing the results obtained with the gold standard amended medium method. Methods were compared intraspecifically and interspecifically. Spearman correlation (nonparametric) and Lin's concordance correlation (parametric) were presented because of the presence of some isolates with high leverage in the linear models. The results of the correlation analysis indicated that the high-throughput assay produced accurate data compared with the amended medium assay but that it may have lacked precision compared with the gold standard amended medium assay. Therefore, double checking the sensitivity using the amended medium assay may be warranted depending on the study objectives. Furthermore, although the $R^{2}$ adj for the intraspecific comparison was lower than desired, the $\mathrm{EC}_{50}$ values were significantly correlated between methods, indicating that the $\mathrm{EC}_{50}$ values for each isolate were similar regardless of method. The largest difference in mefenoxam $\mathrm{EC}_{50}$ values when comparing the high-throughput assay with the amended medium assay among Pythium oopapillum isolates was $0.23 \mu \mathrm{g} \mathrm{ml}^{-1}$ (isolate 148). However, the $\mathrm{EC}_{50}$ for isolate 148 was $<0.5 \mu \mathrm{g} \mathrm{ml}^{-1}$ in both methods. Practically, this difference would not result in misclassification of an isolate as resistant when it was sensitive. To provide additional validation of the high-throughput assay, we compared the methods interspecifically with a larger range of fungicide sensitivity including resistant and sensitive isolates. Sensitive and resistant isolates were always correctly classified.

The assay presented consistently produced high-quality data comparable with those obtained using the amended medium assay. The high-throughput method can quickly screen hundreds of isolates within a species or across numerous species, making it amenable for phenotyping fungicide sensitivity of oomycete populations and communities. Because considerable variation in species sensitivity to ethaboxam existed, effort should be spent on molecular mechanisms of fungicide resistance in these species. The high-throughput method enables fungicide sensitivity studies at the population or community level, which will aid in more precise management of disease-causing oomycete species.

\section{ACKNOWLEDGMENTS}

We thank the Oomycete Soybean Cooperative Agricultural Project extension team, Mary Hausbeck, and Johanna Del Castillo Munera for isolates used in this study. We also thank Dair McDuffee and Jie Wang for their helpful discussions and technical assistance. Lastly, we acknowledge Hao-Xun Chang and Hyunkyu Sang for their helpful suggestions editing this manuscript.

\section{LITERATURE CITED}

Bates, D., Mächler, M., Bolker, B., and Walker, S. 2015. Fitting linear mixedeffects models using lme4. J. Stat. Softw. 67:1-48.

Beakes, G. W., Glockling, S. L., and Sekimoto, S. 2012. The evolutionary phylogeny of the oomycete "fungi.". Protoplasma 249:3-19.

Birmingham, A., Selfors, L. M., Forster, T., Wrobel, D., Kennedy, J., Shanks, E., Santoyo-Lopez, J., Dunican, D. J., Long, A., Kelleher, D., Smith, Q., Beijersbergen, R. J., Ghazal, P., and Shamu, C. E. 2009. Statistical methods for analysis of high-throughput RNA interference screens. Nat. Methods 6: 569-575.

Brent, K. J., and Hollomon, D. W. 2007. Page 25 in: Fungicide Resistance: The Assessment of Risk. FRAC Monograph No. 2. Global Crop Prot. Fed., Brussels, Belgium.

Buchser, W., Collins, M., Garyantes, T., Guha, R., Haney, S., Lemmon, V., Li, L., and Trask, O. 2012. Assay development guidelines for image-based high content screening, high content analysis and high content imaging. Pages 60-65 in: Assay Guidance Manual. G. S. Sittampalam, N. P. Coussens, K. Brimacombe, A. Grossman, M. Arkin, D. Auld, C. Austin, J. Baell, B. Bejcek, and T. D. Y. Chung, eds. Eli Lilly \& Company and the National Center for Advancing Translational Sciences, Bethesda, MD.

Chai, S. C., Goktug, A. N., and Chen, T. 2015. Assay validation in high throughput screening - from concept to application. Pages 221-239 in: Drug Discovery and Development-From Molecules to Medicine. O. Vallisuta and S. Olimat, eds. InTech Open Limited, London, United Kingdom.

Cohen, Y., and Gisi, U. 2007. Differential activity of carboxylic acid amide fungicides against various developmental stages of Phytophthora infestans. Phytopathology 97:1274-1283.

Cox, K. D., Quello, K., Deford, R. J., and Beckerman, J. L. 2009. A rapid method to quantify fungicide sensitivity in the brown rot pathogen Monilinia fructicola. Plant Dis. 93:328-331.

Del Castillo Múnera, J., and Hausbeck, M. K. 2016. Characterization of Pythium species associated with greenhouse floriculture crops in Michigan. Plant Dis. 100:569-576.

Förster, H., Kanetis, L., and Adaskaveg, J. E. 2004. Spiral gradient dilution, a rapid method for determining growth responses and $50 \%$ effective concentration values in fungus-fungicide interactions. Phytopathology 94:163-170.

Frac, M., Gryta, A., Oszust, K., and Kotowicz, N. 2016. Fast and accurate microplate method (Biolog MT2) for detection of Fusarium fungicides resistance/sensitivity. Front. Microbiol. 7:1-16.

Garbelotto, M., Harnik, T. Y., and Schmidt, D. J. 2009. Efficacy of phosphonic acid, metalaxyl-M and copper hydroxide against Phytophthora ramorum in vitro and in planta. Plant Pathol. 58:111-119.

Georgopoulos, S. G. 1982. Detection and measurement of fungicideresistance. Pages 24-31 in: Fungicide-Resistance in Plant Protection. J. Dekker and S. G. Georgopoulos, eds. Pudoc, Wageningen, The Netherlands.

Govers, F. 2001. Misclassification of pest as 'fungus' puts vital research on wrong track. Nature 411:633.

Hughes, J., Rees, S., Kalindjian, S., and Philpott, K. 2011. Principles of early drug discovery. Br. J. Pharmacol. 162:1239-1249. 
Hunter, S., McDougal, R., Clearwater, M. J., Williams, N., and Scott, P. 2018. Development of a high throughput optical density assay to determine fungicide sensitivity of oomycetes. J. Microbiol. Methods 154:33-39.

Huzar-Novakowiski, J., and Dorrance, A. E. 2018. Genetic diversity and population structure of Pythium irregulare from soybean and corn production fields in Ohio. Plant Dis. 102:1989-2000.

Jeffers, S. N. 1986. Comparison of two media selective for Phytophthora and Pythium species. Plant Dis. 70:1038-1043.

Kuhajek, J. M., Jeffers, S. N., Slattery, M., and Wedge, D. E. 2003. A rapid microbioassay for discovery of novel fungicides for Phytophthora spp. Phytopathology 93:46-53.

Lenth, R. V. 2016. Least-Squares Means: The R package lsmeans. J. Stat. Softw. 69:1-33.

Lin, L. K. I. 1989. A concordance correlation coefficient to evaluate reproducibility. Biometrics 45:255-268.

Lookabaugh, E. C., Ivors, K. L., and Shew, B. B. 2015. Mefenoxam sensitivity, aggressiveness, and identification of Pythium species causing root rot on floriculture crops in North Carolina. Plant Dis. 99:1550-1558.

Luo, L., Ho, H. H., and Jong, S. C. 1988. Study on the physiological characteristics of the genus Phytophthora. Mycotaxonomy 32:199-217.

Martin, F. N., and Loper, J. E. 1999. Soilborne plant diseases caused by Pythium spp.: Ecology, epidemiology, and prospects for biological control. Crit. Rev. Plant Sci. 18:111-181.

Martin, S., Buehler, G., Ang, K. L., Feroze, F., Ganji, G., and Li, Y. 2012. Cellbased RNAi assay development for HTS. Pages 11-19 in: Assay Guidance Manual. G. S. Sittampalam, N. P. Coussens, K. Brimacombe, A. Grossman, M. Arkin, D. Auld, C. Austin, J. Baell, B. Bejcek, and T. D. Y. Chung, eds. Eli Lilly \& Company and the National Center for Advancing Translational Sciences, Bethesda, MD

Noel, Z. A., Wang, J., Chilvers, M. I., and Sciences, M. 2018. Significant influence of $\mathrm{EC}_{50}$ estimation by model choice and $\mathrm{EC}_{50}$ type. Plant Dis. 102:708-714.

Olson, H. A., Jeffers, S. N., Ivors, K. L., Steddom, K. C., Williams-Woodward, J. L., Mmbaga, M. T., Benson, D. M., and Hong, C. X. 2013. Diversity and mefenoxam sensitivity of Phytophthora spp. associated with the ornamental horticulture industry in the southeastern United States. Plant Dis. 97:86-92.

R Core Team. 2017. R: A Language and Environment for Statistical Computing. R Foundation for Statistical Computing, Vienna, Austria.
Rampersad, S. N. 2011. A rapid colorimetric microtiter bioassay to evaluate fungicide sensitivity among Verticillium dahliae isolates. Plant Dis. 95: 248-255.

Ritz, C., and Streibig, J. C. 2005. Bioassay analysis using R. J. Stat. Softw. 12: 1-22.

Rojas, J. A., Jacobs, J. L., Napieralski, S., Karaj, B., Bradley, C. A., Chase, T., Esker, P., Giesler, L., Jardine, D., Malvick, D., Markell, S., Nelson, B. D., Robertson, A., Rupe, J. C., Smith, D., Sweets, L., Tenuta, A., Wise, K., and Chilvers, M. I. 2017a. Oomycete species associated with soybean seedlings in North America. Part I. Identification and pathogenicity characterization. Phytopathology 107:280-292.

Rojas, J. A., Jacobs, J. L., Napieralski, S., Karaj, B., Bradley, C. A., Chase, T., Esker, P. D., Giesler, L. J., Jardine, D. J., Malvick, D. K., Markell, S. G., Nelson, B. D., Robertson, A. E., Rupe, J. C., Smith, D. L., Sweets, L. E., Tenuta, A. U., Wise, K. A., and Chilvers, M. I. 2017b. Oomycete species associated with soybean seedlings in North America. Part II. Diversity and ecology in relation to environmental and edaphic factors. Phytopathology 107:293-304.

Schaad, N. W., and Frederick, R. D. 2002. Real-time PCR and its application for rapid plant disease diagnostics. Can. J. Plant Pathol. 24:250-258.

Sebaugh, J. L. 2011. Guidelines for accurate EC50/IC50 estimation. Pharm. Stat. 10:128-134.

Sui, Y., and Wu, Z. 2007. Alternative statistical parameter for high-throughput screening assay quality assessment. J. Biomol. Screen. 12:229-234.

Sutula, C. L., Gillett, J. M., Morrissey, S. M., and Ramsdell, D. C. 1986. Interpreting ELISA data and establishing the positive- negative threshold. Plant Dis. 70:722-726.

Vega, B., Liberti, D., Harmon, P. F., and Dewdney, M. M. 2012. A rapid resazurin-based microtiter assay to evaluate QoI sensitivity for Alternaria alternata isolates and their molecular characterization. Plant Dis. 96: 1262-1270.

Zelaya-Molina, L. X., Ortega, M. A., and Dorrance, A. E. 2011. Easy and efficient protocol for oomycete DNA extraction suitable for population genetic analysis. Biotechnol. Lett. 33:715-720.

Zhang, J. H., Chung, T. D. Y., and Oldenburg, K. R. 1999. A simple statistical parameter for use in evaluation and validation of high throughput screening assays. J. Biomol. Screen. 4:67-73. 